\title{
Sustainable Groundwater Stories - From Disasters to Epical Narration
}

\section{INTRODUCTION}

Fiction writers rarely imagine water's subterranean realms. Novelists tend not to encroach beneath the predominant attention to surface water to find the potency of groundwater narratives. This paper examines the deep, time connections of water and story. Blending post-human imaginaries with the politics of Australian water cultures and drawing from Val Plumwood's "shadow places", the paper applies the notion of "shadow waters" 1 to creative writing methodologies. Telling disaster stories is not enough. Narrating the vulnerabilities and potencies of groundwater's tidal movements means linking ancient pasts with perilous futures through the precarious present. Acknowledging the long tradition of Indigenous oral story lines, Alexis Wright's "epical storytelling" in Carpentaria is exemplary. ${ }^{2}$ What can be learnt of sustainable groundwater ecologies and incursions into groundwater management from stories that give voice and representation to aquifers themselves?

Tell a story of the underground in Western literature and it is hard to shuck the myths and realities of hellish places. Adding water to the mix calls upon a different metaphoric nuance. Planet Earth, with its molten core and shifting tectonic mantel, circles the sun at just the right distance to enable water to exist in liquid form at the surface. Water covers just over seventy percent of the earth's surface. Water preceded the delta-like weavings of evolutionary unfolding of a vast array of life forms. Water, in each moment, enables continuity of the planet's extraordinarily diverse ecosystems. Storytellers have drawn upon the metaphoric potency of water across millennia and across cultures. However, focusing here on an Australian context, stories of groundwater are not common because for most people it is difficult to see or imagine. ${ }^{3}$ The alchemy of water seeping through deep subterranean spaces provokes groundwater stories that, I shall argue, need to be written to respond to groundwater's increasing vulnerabilities. You might be taken to deep and murky places in your imaginings. You might at least come to see connections that are rarely made. Here I discuss various approaches to writing groundwater narratives, arguing for the political and environmental necessity of literary representations of groundwater's potency. In thinking of how to express the voices of groundwater, I am reminded that geological forces and structures behind 
groundwater's movements existed long before the blip of human-induced damages that are now recorded as a geological era. The Anthropocene is a term which recognises the planetary scale of human influences on worldwide geologies, as well as irremediable changes to ecosystems, soil and water chemistries and global temperatures. Anthropogenic activities have also had devastating effects on groundwater.

Over-extraction, meaning pumping aquifers beyond their capacity to recharge, and pollution of subterranean waters are the two main anthropogenic injuries being inflicted on this generally unseen part of the global water cycle. Groundwater's vulnerability to human exploitation belies its potency as a significant water source, and its poorly understood place in Australian cultural history and narratives. Concentrating on Australian circumstances, the merging of scientific discourse and knowledge with literary storytelling offers a way to understand groundwater more deeply and ultimately offers protection of sustainable groundwater ecosystems. Current inaction on groundwater's perilous circumstances may, I propose, be positively affected by thinking through groundwater narratives. Stewardship of ecologically sustainable groundwater includes finding the stories that instigate new ways of thinking with "shadow water". ${ }^{4}$

I start by exploring interpretations of underground encounters, in particular through Robert MacFarlane's deep time journey in Underland (2019). ${ }^{5}$ I read this text through the lens of "shadow waters" as a way to illuminate groundwater narratives that embody consideration of the power structures' intersections with cultural practices. I next consider the possibilities and limits of writing speculative disaster stories, in particular the stories of floods and tempests, within the climate fiction (cli-fi) genre. ${ }^{6}$ Thirdly, I explore Alexis Wright's ideas of "epical storytelling", demonstrating how contemporary Indigenous perspectives are uniquely positioned to tell sustainable groundwater stories. ${ }^{7}$ Examining expressions of groundwater in Wright's Carpentaria illustrates the "uses of literature", whereby readers may recognise ourselves, gain new knowledge and rupture familiar frames of reference. ${ }^{8}$ I propose the importance of building cultural narratives of groundwater, writing untold stories that contribute to sustainable groundwater practices.

\section{UNDERGROUND ENCOUNTERS WITH SHADOW WATERS}

The allure of dark and unseen places has occupied literary curiosity across eons. Mythological underworlds such as Hades and the five starless rivers that flow there have been fodder for storytellers for millenniums. ${ }^{9}$ Orpheus' journey to Hades to rescue his deceased wife, Euridice, is perhaps one of the earliest narratives to feature subterranean waters. Foundational iterations in the Western literary tradition include Dante's Divine Comedy written in the early fourteenth century to describe the author's imagined journey into the afterlife. Below the surface stories are often about death, the underground being the place of the dead. Such stories of rivers passing into mountains, of underground deluges, as MacFarlane explains, often derive from karst country, places where water dissolves limestone, dolomites and gypsums to create disappearing rivers, sinkholes and lakes that appear to fill automatically. ${ }^{10}$ These underground stories can explicate subterranean life forms and also create elucidative analogies to human lives.

Fascination with subterranean spaces came to the surface when, in June 2018, the world watched agape as twelve young Thai footballers were lost, found and rescued after being trapped deep underground. ${ }^{11}$ The effect of tropical storms on groundwater movements through deep chasms in the Tham Luang cave complex had trapped the boys and their teacher for ten days, before rescuers 
were able to find them. Global media focused world attention on the dangers of the underworld. Though ideas of water's mysterious and dangerous movements underground have long attracted adventurers and cave divers, Western literary narratives have only cautiously entered this domain. In comparison, Indigenous storytellers have for millennia included an appreciation of groundwater, "characterising it through contextual layers of creation stories" which remain paramount in contemporary Aboriginal law and legal obligations. ${ }^{12}$

Groundwater stories have had scant attention in Australian settler literature.13 Groundwater is not readily "seen", and its extraction by agriculture, the mining industry and by communities for domestic use is enmeshed in labyrinthine bureaucratic and legislative guidelines. The concept of "shadow waters" is derived from Val Plumwood's ${ }^{14}$ engagement with "shadow places", which applies a social justice and gendered lens to analysing the politics of place. In a similar vein,

Shadow waters draws attention to the cultures and relations that privilege certain water values and knowledges while rendering other water value invisible and marginalised in mainstream water management practices and planning processes. Shadow waters are metaphorical in the sense that particular water values are "hidden" or "demoted" in favour of other, and literal, for example groundwater is not as visible to most humans as surface water. ${ }^{15}$

Perhaps consequentially it has been surface water stories that have garnered the attention of nonfiction writers. Focussing on the dire state of the Murray-Darling Basin river systems that cover almost a quarter of the south-eastern corner of Australia, journalistic stories abound of dry rivers, fish kills and unscrupulous water usage by cotton, grain and almond growers from the Murray River to the far north-west of New South Wales. Margaret Simons' outstanding essay “Cry me a River: The Tragedy of the Murray-Darling Basin" explores the complex politics, geographies, community entanglements and water economics that underlies decades of conflicts, bureaucratic slip-knots and slip ups, and ultimately the failure of the river systems to survive blundering human interventions. ${ }^{16}$ Driving the length and breadth of the Murray-Darling Basin and speaking with key players on all sides of numerous fences, Simons' essay reveals the close-up wicked dilemmas and an aerial overview of shocking mismanagement across the primary food bowl of the Australian continent.

In comparison, the fictional novel The Last Pulse, by Anson Cameron, ${ }^{17}$ tells a rollicking tale of Merv Rossiter, bereaved father come-eco-activist who, with his daughter Em, breaches a thinly disguised Cubby Station mega-dam in cotton country with a stick of gelignite. In a bucket-like tinny named The Party Animal, they surf the torrent of released waters down the Darling River, joined by a hapless politician, Brigit Wray, and a young Aboriginal boy, Barwon. Merv wanted to see water flowing again in the parched reaches of the Murray River in South Australia, so takes action into his own hands when water politics and market-driven economics lead to the down-stream waters of the MurrayDarling system being stolen, squandered and misused higher in the basin's cupped hand.

Reading these two different approaches to stories of water and ecology, it is possible to see how fiction speaks as clearly as non-fiction of the river's plight. In twentieth and twenty-first century Australian literature, surface water stories often portray drought or flood. Among numerous examples, Beverly Farmer's This Water: Five Tales, Alice Robinson's Anchor Point, Angela Harper's The Dry, and Thea Astley's Drylands, each convey water's roles in communities and in individual character's lives. ${ }^{18}$ A preoccupation with drought and flood follows settler colonialist perceptions 
of Australian landscape. Stories of agricultural practices that are often ill-suited to Australian conditions bemoan ephemeral waterways. Extant but rare, groundwater stories could potentially show aquifers' responses to anthropogenic climate change in a different register to scientific discourse. Such stories are generally, however, composed from within the limits of colonising perspectives. McLean et al. draw attention to an engagement with the parameters of shadow waters as a means to incorporate cultural dimensions of the "hydro-social cycle" into eco-fiction and non-fiction water narratives. ${ }^{19}$

\section{SPECULATIVE DISASTER STORIES AND NEW REALIST FICTIONS}

Fiction writers, along with many cultural commentators, have suffered from what Amitav Ghosh calls "the great derangement", meaning our inability or perhaps unwillingness to attempt to narrate the complexity of environmental disasters that may have various local expressions, but exist within a wider context of global warming. ${ }^{20}$ However, long before and since Ghosh's complaint, numerous authors have written about the multiple effects of climate catastrophes. Climate fiction, or cli-fi, sometimes named Anthropocene fictions or climate change fiction, refers to fictional accounts of the causes and effects of climate change, and provides insights into the dominant Western imaginaries of climate change events to individuals and communities. ${ }^{21}$ In his cultural analysis of climate fiction in the Anthropocene, Gregers Andersen explores the wide array of climate fictions that have emerged in response to scientific announcements of anthropogenic contributions to global warming over the past thirty years. Annual reports from the Intergovernmental Panel on Climate Change reports have long foreshadowed the world's water crisis. Fiction writers are increasingly finding ways to tell these catastrophic stories.

Climate fiction has become a fast-growing genre, with an escalating number of such speculative fictions published over the past ten years. Human transgression and violations of environments is a well-established literary theme, and has been written into stories for centuries. ${ }^{22}$ Numerous climate fiction writers are attempting to expose the growing list of climate change induced environmental destructions through narratives of plausible causes and effects. Most of these remain speculative, and are founded on varying degrees of scientifically proposed facts.

When climate fiction writers have turned their attention to anthropogenic climate catastrophes, disaster narratives of floods and deluge provide a common structure to focus attention upon the effects of global warming. ${ }^{23}$ Trexler chronicles a selection of Anthropocene fiction that takes up stories of flood and tempest to illustrate fictional examples of the devastating effects of water's responses to climate change. ${ }^{24}$ Fictional speculations of water's power to wash away communities are often set in futurist and conjectural worlds, for example Doris Lessing's Mara and Dann, JG Ballard's The Drowned World and Maggie Gee's The Flood. ${ }^{25}$ Such fictions may describe communities where particular members have "sinned", where conflicts over approaches to water management are not resolved for the greater good, or where authorities have not heeded the warnings of global warming. Where floods are imagined, and "sins" are washed away by the powers of the watery non-human world, surviving humans are free to continue being destructive humans. ${ }^{26}$ Ultimately, little changes in human views of our relationships with water: water remains shadowy.

Katie Ritson analyses the complexities of stories about inundations in a European context. ${ }^{27}$ She selects literature from the past two centuries to explore the different ways that the "shifting sands of the North Sea Lowlands" have been fictionalised. She highlights literary case studies that centre 
around the flooding of coastlines around the North Sea, focusing on selected texts from the United Kingdom, the Netherlands and Scandinavian countries. These liminal low-lying landscapes are read as bellwethers for the effects of climate change. The texts she analyses predominantly reveal human efforts to engineer landscapes into submission. From the dykes of the Netherlands to the oil rigs across the North Sea, human hubris is revealed. Ritson proposes that various authors' imaginations and depictions of the multiple threats of flooding portray the capacity of literature to illustrate water's agency. She uses the term "Anthropocene fictions", as does Trexler, ${ }^{28}$ to convey the Western rationalist way of thinking that imagines not only human responsibility for worldwide water crises, but an expectation that it will be humans that solve the problems. Such a position belies the true potency of water to determine its own place and global power, and detracts from authorial potential to give greater voice to more-than-human entities, particularly water's many forms - fogs, mists, tides, rivers, lakes.

An example of Australian speculative fiction, James Bradley's Clade, ${ }^{29}$ follows an intergenerational cluster of characters linked by the protagonist, Antarctic scientist Adam Leith, across decades of change. Dramatic storms and floods in the United Kingdom are the backdrop to Adam's efforts to find and save his daughter and grandson and return them to Australia. Throughout the novel, Bradley consciously and consistently draws the reader's attention to a range of ongoing planetary disasters, from overpopulation and pandemics, to beehive collapse that lead to food shortages. Water's role in this novel is predictably surface oriented. Groundwater barely rates a mention.

The loss of aquifers has every chance of inspiring well-written disaster stories. As a result of over extraction or pollution, groundwater's capacity to continue its ecological roles, including its capacity to maintain river flows, to fill swamps, to water forests, to sustain rare aquatic species and subterranean stygofauna, and to instigate springs that bring life to the most remote parts of the country, is seriously compromised. Groundwater has innumerable stories to tell. The challenge remains to develop engaging fiction that moves beyond the surface disasters of the Anthropocene, to stories that connect human and non-human actors in sustainable collaborations. Groundwater stories, which may be about local impacts, must also show a global context, as well as the entanglements of aquifers and humans. The global water cycle is an enormous palette from which authors might portray the realities of the connectivity between surface waters and beneath the surface shadow waters, as well as human relationships to diverse watery places. Shadow waters provides a framework for such narratives.

In taking a hydrological turn, authors of fiction face the challenge of breaking free from "anthropocentric logics of efficiency, profit and progress" where water is given a "passive role as "resource" and subjected to containment, [and] commodification." ${ }^{30}$ In this process, writers are challenged to invent new language, new forms of voice and representation of our relationships with the world. ${ }^{31}$ Groundwater is often an invisible player, expected to be a backdrop or to lie beneath human conflicts and dramas. "It is not only the urgency of the impacts of climate change on groundwater that are of interest; it is groundwater's scale and invisibility, that it cannot be directly experienced in the manner that we may experience a flood, storm and tempest, that puts it in need of narration, now." ${ }^{32}$ Human conflicts over water use drives politics and economics, and involves high stakes. ${ }^{33}$ Applying these stakes to groundwater's perilous circumstances through fictional narratives is the task ahead. ${ }^{34}$ It is how these stories might be told that will determine their resonance and lifespans. 


\section{EPICAL STORYTELLING - GROUNDWATER'S TIMESCALES}

In contrast to how a range of non-Indigenous writers have responded to (or not responded to) stories of surfacewater and groundwater, Indigenous thinkers and writers have engaged with water narratives from distinctively cultural perspectives. A practitioner of what has been described as Aboriginal realism, Indigenous author Alexis Wright reconfigures relationships to water, time and place by exploring groundwater's subterranean connections to Waanyi Dreamtime in Australian cultural imaginaries. ${ }^{35}$ The form of epical storytelling that Wright takes up encompasses the ancient stories of ancestral creation beings, and builds on the original literature of the Australian continent. ${ }^{36}$

Wright's novel, Carpentaria, acknowledges the mythic place of underground waters in the creation stories of the Waanyi people of the Gulf of Carpentaria, in northern Australia. Much of the multi-vocal, multi-perspective, poetic depictions of Gulf Country in Carpentaria are washed with thunderous storms and deluge. The novel also follows the story of senior law man Normal Phantom and his son, Will Phantom, who struggle against mining of their Country. Beneath the multi-layered plotline, we hear the deep-time power of the land and waters. Wright tells an epic story in the voices of her ancestors, at times in the voice of Country itself. In her description of the conflicts between Indigenous and non-Indigenous residents of the fictional Gulf township, Desperance, Wright intertwines ancient and contemporary stories of Indigenous law and culture. She refers to her writing as a form of epical storytelling, "the ancient stories of the ancestral creation beings that are learned and stored as mind maps that define the philosophical understanding of Aboriginal law, and which, taken together, embrace the entire continent." ${ }^{37}$ Wright discusses the work of poets to excavate deeply within souls and psyches to help us make sense of ways to be human. ${ }^{38}$

The influential power of cultural connection to waters and Country underpins the lyric and galloping storytelling in Carpentaria. Wright lays out the foundations of the Serpent narration and the Serpent creation of rivers and Country near the start of the novel. She writes:

This is where the giant serpent continues to live deep down under the ground in a vast network of limestone aquifers. They say its being is porous; it permeates everything. It is all around in the atmosphere and is attached to the lives of the river people like skin. ${ }^{39}$

Wright invokes the "naturalness of being fully in touch with the antiquity of this world as it is now" to assist our understandings of future possibilities. ${ }^{40}$ She reminds us that the poetics of writing are often formed in hidden places, and asks writers to dig deep, to dwell in such places. How non-Indigenous writers might respond to her challenge raises important questions around appropriative or extractive practices in relation to telling Indigenous stories. Wright has often drawn attention to Aboriginal disempowerment, produced through the colonial practices of "telling someone else's story." ${ }^{41}$ In what Wright calls a "storytelling war", non-Indigenous writers have consistently incorrectly presumed a capacity to represent Indigenous worlds and experiences to which they have limited access. When I draw attention to Wright's ability to bring groundwater's voices to light, it is as an act of listening to her narrative, rather than as telling stories beyond the limits of my white settler perspective. The ethics of listening to epical storytelling entails following stories across vast timeframes, putting aside the lineal and oppositional restrictions of Western Enlightenment patterns of thought. The concept of shadow waters invites analysis of the blurry 
spaces where water's power as a narrative force is acknowledged. Wright places both surface and subterranean waters front and centre and invites readers to listen to the sounds and voices of ancient epical water stories. For example, as Will Phantom awaits the coming of a tropical storm, Wright shows his understanding of water's powers:

He became conscious of what the sea ahead was doing once more, and although he knew it was kilometres away, he heard the spirit waves being rolled in by the ancestral sea water creatures of the currents, and conspiring with the spirits of the sky and winds to crash into the land as though it was exploding. The earth murmured, the underground serpent, living in the underground river that was kilometres wide, responded with hostile growls. ${ }^{42}$

Throughout Carpentaria, groundwater is the dwelling place of Aboriginal law. While Carpentaria folds over and over itself through palimpsests of time and place, in Wright's own words this is not magic realism, nor speculative fiction. Instead, Jeanine Leanne's characterisation of the book as "Aboriginal Realism" lets us understand the absolute relevance of the book to ongoing contemporary experiences of racism and colonialist violence..$^{43}$ Using the term "Aboriginal Realism" acknowledges that Wright consciously interweaves past, present and future, and spiritual and material planes, not merely as generic textual play but as an enactment of Indigenous thinking and philosophy. "Carpentaria challenges ideas of boundaries and confinement by exploring how ancient Aboriginal beliefs sit in the contemporary world as a continuation of our Dreaming stories." 44 As Alison Ravenscroft ${ }^{45}$ explains, white readers, writers and critics of magic realism have replicated imperialist tendencies whereby the emphasis is about different subjects (colonised/colonisers; Indigenous/white). Significantly the "magic" is attributed to the colonised "other" person, the Indigenous signed text. The "reality" or "realism" is ascribed to the rationalist knowledge of the seeing and knowing imperialist coloniser. ${ }^{46}$ For Ravenscroft, the literary take up of "magical realism" is another way of re-inscribing Indigeneity with magic, delusion and dream, and whiteness with realism, reality and rationalism. ${ }^{47}$ This, she argues, is another form of imperialism or colonialism.

By entwining stories of the ancient past with the contemporary experiences of Indigenous Australians, Carpentaria invites prescient perceptions of future relations between all Australians. Seeping throughout the text, Wright's narrators, particularly protagonist Normal Phantom, show the influence of Indigenous knowledges and beliefs from across millennia through their custodial relationships with rivers, oceans and the subterranean waters. Wright's characters, while bearing the grief and pain of colonial violence, theft and misappropriation, retain connections to ancient stories. Yet as non-Indigenous readers we can never really know or see the places or laws that govern the lives of Wright's characters. Non-Indigenous readers enter a partial relationship with this text, retaining responsibility to engage with the shadow waters and the shadow places that Wright reveals. The novel uncovers the perils of an extractive approach to reading Indigenous stories, as imaginaries are appropriated in a similar way to plundering and theft of minerals and groundwater taken from Indigenous Country. Wright points towards what can be learned from continual, living relations to place. As readers listen to the musicality in her text, the enduring nature of a culture that has shown sustainability for over 60,000 years can be approached but never truly comprehended.

There is an ethical and political imperative to stories of environmental sustainability. Wright's novel enables the voices of non-human entities to take their place alongside human narratives. Finding a balance of anthropocentric voices with the voices of non-human entities demands a 
shift in thinking and a shift in writing. Giving voice to more-than-human entities, as Wright has, is part of a sustainable ethics of storytelling because it gestures towards fracturing the assumed hegemony of anthropocentric discourse. Acknowledging relationality between human and morethan-human entities enables Wright to hear wider ecological and cultural resonances. "Storying" with groundwater demands new languages and a depth of engagement with emotions, to express unheard relationships with water. ${ }^{48}$ Wright accomplishes this in Carpentaria through her commitment to the stories of her ancestors, to tell the stories of the land itself, through a potent contemporary lens. Most significantly she tells the stories of water's agency and power. The very last paragraph of the novel encapsulates water's potency, its life-giving and life-taking powers: "It was a mystery, but there was so much song wafting off the watery land, singing the country afresh as they walked hand in hand out of town ..."..$^{49}$

I acknowledge the blurred boundaries between Wright's fictional worlds, between the resonances of the shadowed realities that readers may or may not discern. I remain hopeful that finding metaphor and analogy in the subterranean existence and journeys of groundwater may provide ways to develop and foster dialogue within the fraught relations between Indigenous and nonIndigenous Australians. To illustrate the difficulty of developing this narrative, the National Water Initiative, introduced in Australia in 2004 by the then Howard Liberal government, separated the legal understanding of water from the land, making water a new category of property right. ${ }^{50}$ In Aboriginal Law, water and land cannot be separated. Access to either surface water or groundwater licences does not take account of cultural connections to water's storied potency. There is a long way to go before the notions of "aqua nullius" will be overturned. ${ }^{51}$

Denial of water's place in Australian cultural narratives hinges upon white settler denial of Aboriginal sovereignties. Persistent epistemologies that see water as a resource, something to be taken, limits a productive way forward. Literature, and in particular evocative eco-critical narrative, represents one way to change cultural imaginaries and to expose the conflicts and dire consequences of contemporary anthropocentric water management practices. Non-Indigenous Australians need to go beneath the surface, become familiar with subterranean worlds in order to better understand both the country they live upon and the laws and sovereign peoples to which it has always belonged. Strengthening relationships with Aboriginal Australia includes listening to and responding respectfully to Indigenous texts that show the significance of Aboriginal water rights. Hearing the voices of water in Alexis Wright's novel, Carpentaria, is one step towards a regenerative relationship with water and with Aboriginal Australians. Groundwater stories are integral to understanding unique and diverse environmental relationships and to preserving the ecosystems that groundwater supports. Engaging with concepts of shadow waters entails taking account of the imbalanced power relations that currently control groundwater extractions. Telling these stories is more important than ever.

Deborah Wardle ( (D) ORCID No 0000-0003-2942-7510) is a writer, teacher and researcher with stories and peerreviewed articles published in Australian and international journals including Meanjin, Overland, The Big Issue, Meniscus, Mosaic (Canada), Fusion, and Animal Studies Journal. Deborah teaches literature at RMIT and Creative Writing at University of Melbourne. Her PhD thesis explores the ways climate fiction expresses groundwater's potency and vulnerability in Australian narratives. 
1. Jessica McLean, Aleshia Lonsdale, Laura Hammersley, Emily O'Gorman, and Fiona Miller, "Shadow Waters: Making Australian Water Cultures Visible," Transactions of the Institute of British Geographers 43, no. 4 (2018): 615-629.

2. Alexis Wright, Carpentaria, (Giramondo Publishing Company, Artarmon, 2006); and Alexis Wright, "On Writing Carpentaria," Heat 13, 2006 (reprinted from Harper's Gold).

3. Deborah Wardle, "Storying With Groundwater: Why We Cry" (PhD Thesis, RMIT Research Repository, 2019). http://researchbank.rmit.edu.au/view/ rmit:162638, accessed April 29, 2020.

4. Cecilia Chen, Janine MacLeod, and Astrida Neimanis, Thinking With Water (Montreal: McGillQueens University Press, 2013); see also McLean et al., "Shadow Waters," 615-629.

5. Robert MacFarlane, Underland: A Deep Time Journey (UK: Hamish Hamilton, 2019).

6. Adam Trexler, Anthropocene Fictions: The Novel in a Time of Climate Change (Charlottesville: University of Virginia Press, 2015).

7. Alexis Wright, "Questions of Fear" in Tolerance, Prejudice and Fear: Sydney Pen Voices the 3 Writers Project, Christos Tsiolkas, Gideon Haigh and Alexis Wright (NSW: Allen \& Unwin, 2008).

8. Rita Felski, The Uses of Literature (Malden, MA: Blackwell Publishing, 2008), 105.

9. Macfarlane, Underland, 177-180.

10. Macfarlane, Underland, 178.

11. Marc Aronson, Rising Water: The Story of the Thai Cave Rescue (Cammeray NSW: Simon \& Schuster, 2019).

12. Virginia Marshall, Overturning Aqua Nullius: Securing Aboriginal Water Rights (Canberra: Aboriginal Studies Press, 2017).

13. Wardle, "Storying With Groundwater."

14. Val Plumwood, "Shadow Places and the Politics of Dwelling," Australian Humanities Review 44: (March 2008).

15. McLean et al., "Shadow Waters," 616.

16. Margaret Simons, "Cry me a River: The Tragedy of the Murray-Darling Basin," Quarterly Essay 77: (2020).

17. Anson Cameron, The Last Pulse (Sydney: Vintage Random House Australia, 2014).

18. See Beverley Farmer, This Water: Five Tales (Artarmon, NSW: Giramondo Publishing, 2017); Alice Robinson, Anchor Point (Melbourne: Affirm Press, 2015); Angela Harper, The Dry (New York: Flatiron Books, 2017); and Thea Astley, Drylands (Camberwell: Penguin, 1999).

19. McLean et al., "Shadow Waters."

20. Amitav Ghosh, The Great Derangement: Climate Change and the Unthinkable, (Chicago, London: University of Chicago Press, 2016).
21. Gregers Andersen, Climate Fiction and Cultural Analysis: A New Perspective on Life in the Anthropocene. (Milton Park: Routledge, 2020), 1-2.

22. See Katie Ritson, The Shifting Sands of the North Sea Lowlands: Literary and Historical Imaginaries (London: Routledge, 2019); Andersen, Climate Fiction and Cultural Analysis; and Trexler, Anthropocene Fictions.

23. Trexler, Anthropocene Fictions, 91.

24. Trexler, Anthropocene Fictions.

25. See Doris Lessing, Mara and Dann: An Adventure (London: Flamingo - Harper Collins, 1999); JG Ballard, The Drowned World (New York: Berkley Books, 1962); and Maggie Gee, The Flood (London: Saqui, 2004).

26. Andersen, Climate Fiction and Cultural Analysis, 47.

27. Ritson, The Shifting Sands of the North Sea Lowlands.

28. Trexler, Anthropocene Fictions.

29. James Bradley, Clade ([Melbourne: Penguin, 2015).

30. Chen et al., Thinking With Water, 3.

31. Glenn Albrecht, "One Hundred Years of Sumbiotude: Resisting the Extinction of Emotions," Griffith Review 68, (2020).

32. Wardle, "Storying With Groundwater," 259.

33. Simons, "Cry me a River."

34. Wardle, "Storying With Groundwater."

35. Jeanine Leanne, "Historyless People," in Long History, Deep Time: Deeping Histories of Place, eds Ann McGrath and Mary Anne Jebb (Canberra: ANU Press, 2015).

36. Wright, "Questions of Fear."

37. Wright, "Questions of Fear," 135.

38. Wright, “Questions of Fear," 136.

39. Wright, Carpentaria, 2.

40. Wright, "On Writing Carpentaria," 11.

41. Ibid.

42. Wright, Carpentaria, 470.

43. Leanne, "Historyless People."

44. Leanne, “Historyless People," 160.

45. Alison Ravenscroft, "Dreaming of Others: Carpentaria and its Critics," Cultural Studies Review 16, no. 2 (2010): 194-224.

46. Ravenscroft, "Dreaming of Others."

47. Ravenscroft, "Dreaming of Others," 197.

48. Wardle, "Storying With Groundwater."

49. Wright, Carpentaria, 519.

50. Marshall, Overturning Aqua Nullius, 14.

51. Marshall, Overturning Aqua Nullius. 